\title{
Becoming a back-up carer: Parenting sons with Duchenne muscular dystrophy transitioning into adulthood.
}

\author{
$\operatorname{AUTHOR}(\mathrm{S})$ :
}

Yamaguchi, Miku; Suzuki, Machiko

\section{CITATION:}

Yamaguchi, Miku ...[et al]. Becoming a back-up carer: Parenting sons with Duchenne muscular dystrophy transitioning into adulthood.. Neuromuscular disorders 2015, 25(1): 85-93

\section{ISSUE DATE:}

2015-01

URL:

http://hdl.handle.net/2433/199610

\section{RIGHT:}

(c) 2014 Elsevier B.V. Licensed under the Creative Commons Attribution-NonCommercial-NoDerivatives 4.0 International http://creativecommons.org/licenses/by-nc-nd/4.0/. NOTICE: this is the author's version of a work that was accepted for publication in Neuromuscular Disorders. Changes resulting from the publishing process, such as peer review, editing, corrections, structural formatting, and other quality control mechanisms may not be reflected in this document. Changes may have been made to this work since it was submitted for publication. A definitive version was subsequently published in Neuromuscular Disorders, Volume 25, Issue 1, Pages 85-93, doi:10.1016/j.nmd.2014.09.001.; 許諾条件により本文ファイルは2016-02-01に公開.; This is not the published version. Please cite only the published version.; この論文は出版社版でありません。引用の際には出版社版をご確認ご利用ください。 
Neuromuscular Disorders 25(2015) 85-93

Becoming a back-up carer: parenting sons with Duchenne Muscular Dystrophy transitioning into adulthood

\author{
Miku Yamaguchi, Machiko Suzuki \\ Department of Human Health Science, Graduate School of Medicine, Kyoto University, \\ Kyoto, Japan
}

Corresponding author:

Miku Yamaguchi: Department of Human Health Science, Graduate School of Medicine, Kyoto

University 53, Kawaracho, Shougoin, Sakyo-ku, Kyoto City, Kyoto Prefecture, Japan, Postcode 6068507. Phone number: +81-75-751-3901; Fax number: +81-75-751-3901

Email: yamaguchi.miku.32w@st.kyoto-u.ac.jp 


\title{
Becoming a back-up carer: parenting sons with Duchenne Muscular Dystrophy transitioning into adulthood
}

\begin{abstract}
The population of adults with Duchenne muscular dystrophy is increasing rapidly. However, information for individuals with DMD and their parents about the transition to adulthood is lacking; young adult sons and their parents may struggle to maintain smooth family functioning and well-being during this period. This study examined the process of change in parental behaviors during their son's transition. The participants were 18 parents with sons aged 15 to 30 years. Data were obtained from semi-structured interviews and analyzed using a grounded theory approach. Eleven categories of behaviors were identified across three domains: emotional, physical, and determination. The changes made by parents were directed toward becoming a back-up carer: letting go of some control but still being active participants in their sons' lives. We identified several issues important for well-being in the transition period: psychological support, the aging of the parents (the primary caregivers) and the concomitant emergency and specialized care needs, and parents' intervention in the self-determination of adult sons with DMD. The findings of this study may provide a rationale to advocate for policies to improve support for parents of sons with DMD transitioning to adulthood and provide information to help parents in their role as primary care providers.
\end{abstract}

Keywords: Duchenne Muscular Dystrophy, parent, transition, young adult, grounded theory 


\section{Introduction}

Duchenne muscular dystrophy (DMD) is a progressive loss-of-function disorder, one of the most common forms of muscular dystrophy [1]. The worldwide incidence is estimated to be 1:3500 male births [2]. In addition to progressive weakness of the skeletal muscles leading to the loss of ambulation by age 10-12 years, DMD patients develop cardiac and respiratory complications that lead to early morbidity and mortality [3]. However, mechanical ventilation can prolong survival into adulthood. Non-invasive assisted ventilation has been shown to improve the quality of life for adolescents and young adults [4]. A survival analysis showed that the mean age of death in the 1960s was 14.4 years, which increased to 25.3 years by the 1990 s for those using ventilation [5]. A recent study reported the estimated probability of survival to age 30 was $85 \%$ due to mechanical ventilation and medical support [6]. Ongoing improvements in medical care for individuals with DMD have led to pressing concerns about well-being in the “unexpected” population of adolescents and adults with DMD emerging over recent years. Today, most children with chronic illnesses achieve some degree of independence and live adult lives [7]. Though a curative treatment is not available, survival into adulthood has become expected for individuals with DMD.

However, information for individuals with DMD and their parents about this transition is lacking. Both young adult sons and their parents may struggle to maintain smooth family functioning and well-being. The aim of this study was to examine the process of change in parental behaviors during their son's transition from childhood to adulthood. The participants were 18 parents with sons aged 15 to 30 years.

\subsection{The transition to adulthood}

In 2011, a Parent Project Muscular Dystrophy Transition Expert Meeting was held to examine and improve the life of young men with DMD during the transition to adulthood [8]. Important 
implications for the medical and social sectors involved in this transition, not only in the move from pediatrics into adult care but also from childhood to adulthood, were addressed. As the report noted, information and guidance for individuals with DMD and their parents in transition may be either lacking or not followed. Additionally, the transition to adulthood was described as a complex, timeconsuming, and ongoing process. In 2012, interviews with young men with DMD and their families were conducted in UK. The findings indicated that parents commonly described their experience of service providers as problematic. It was common for families to describe having to prove their sons' needs repeatedly, and this resulted in fights and battles over independence and self-determination [9]. The survey demonstrated that both sons and their parents were struggling during the transition to adulthood.

Transition from childhood into adulthood of individuals with DMD is a process [8], which Abbott et al. [9] defined as beginning at age 15. In the field of developmental psychology, the period of transition into adulthood has been defined in many different ways [10-12], and a new developmental definition of this psychosocial transition period defines it as occurring from 18 to 25 years of age [13]. In a 2002 statement from the American Academies of Pediatrics and Family Physicians and American College of Physicians-American Society of Internal Medicine, the transition was explained as a long process undergone by individuals with special health care needs as they move from adolescence to adulthood. Therefore, it was suggested that physicians develop a health care transition plan by age 14 as a first step in preparing for the changes; annual updates and updates with any transfer of care were also recommended [14].

1.2 The role of parents

An increasing number of studies have focused on the experiences of parents who have children with DMD. Parental stress, a multilateral finding, has often been identified as an impediment to smooth 
family functioning [15-20]. Nereo et al. [21] reported that parental stress was elevated in the transitional period due to increased problems in social interactions rather than the physical demands of the disease. However, parents were able to adapt to find hope and enrichment beyond the stress [22, 23]. Webb [18] reported that parents demonstrated their resiliency and ability to develop effective coping strategies from their experiences as caregivers.

Some recent studies have focused on parental care for a child with DMD on mechanical ventilation. Ventilation can prolong the life of an individual with DMD; however, the psychological, emotional, and physical burden for parents may be overwhelming. O’Brien [24] interpreted the parental caregiving role as "living in a house of cards"; daily life with a child with DMD may collapse due the enormity of meeting all the caregiving needs and the overwhelming stress [24]. These families experienced the challenge of managing daily life and maintaining functional life. In another study, Mah et al. [25] described parental caregiving as a "lifeline" due to the tremendous devotion required for a mechanical-ventilated dependent child’s daily life and quality of life. The study reported the families’ lives changed significantly with the decision to place their child on mechanical ventilation; the term "lifeline" symbolized the vital role and the weight of the responsibility that parents had assumed to ensure the survival and well-being of their child. Mah et al. [25] suggested that more support by health care professionals was needed to enable parents to fulfill this vital role. These studies increased awareness among physicians and other health care professionals of the reality of parents' life with a child with DMD on mechanical ventilation. However, all these papers included parents with young to mid-teenage children [15-25].

Schrans et al. [8] identified some “taboo” issues for individuals with DMD transitioning into adulthood [8]. One of the taboos was "separation from parental care.” In the transition from teenager to young man to adult, the issue of independence from parents as caregivers surfaces [8]. This issue may become more serious with increasing age due to the progression of disease, dependence on mechanical 
ventilation, and need for specialized care. The role of parents in this transition, whether maintaining their role as a "lifeline” or adapting by changing parenting and caring behaviors, has received little attention.

\subsection{The Grounded Theory Approach}

We selected a grounded theory approach to examine parental behaviors as their son with DMD developed from childhood into adulthood. Grounded theory, which strives to understand human behavior in a social context, originated in the field of sociology [26-28]. It is an appropriate approach for revealing patterns and characteristics though textual data, which may lead to theories of behavior [29]. The goal of grounded theory is to develop an explanatory theory of specific social processes, studied in the environments in which they take place [29]. Researchers collect, code, and analyze the data, using the information to direct further sampling and collection of data, in order to develop a theory [29].

Theoretical sampling is an element of grounded theory and is used to obtain a wide variety of participants within the criteria. As compared to probabilistic sampling, theoretical sampling focuses on the identification and recruitment of participants with different backgrounds. It is an essential part of grounded theory and assists with theory generation; the researcher collects, codes, and analyzes data and decides what data to collect next simultaneously [29].

\subsection{Objectives of the study}

The aim of this study was to examine the process of change in parental behaviors during their son's transition from childhood to adulthood. Our goal was to examine parental behaviors and develop a theory that could explain and capture these changes. Results from this qualitative study may lead to 
advocating for policies to improve support for parents with DMD sons transitioning to adulthood and provide information to help the parents in their roles as primary care providers.

\section{Participants and Methods}

\subsection{Participants}

In this study, we selected the ages covered in the transition to adulthood of DMD individuals based on previous studies [9-14, 30]. We decided that 15-30 years of age was a sufficient range to study the transition from childhood to adulthood. Therefore, the inclusion criterion for this study was being a parent of a son with DMD who was 15-30 years of age.

Using theoretical sampling, we recruited participants from several different locations: two family associations of DMD; two independent living centers; an association of wheelchair-football; and a specialized hospital for muscular dystrophy. These facilities and groups were in different areas in Honshu, the largest island of Japan. The variety of locations led to a sample with diversity in the socioeconomic characteristics of the parents.

The first author (M.Y.), who is not part of their health care team, contacted the administrator of each facility or group and requested an introduction to parents whose DMD sons were 15-30 years of age. We contacted the potential families by phone or in person during their group meetings to invite one parent (mother or father), who was main care provider for their DMD son, to participate in the study. We decided that one parent would be sufficient and this would avoid cross-family influence.

Table 1 shows the characteristics of participants. Eighteen parents (14 mothers and 4 fathers) consented to participate in the interview. All of the participants had one son with DMD; six families included healthy siblings. The median age of their sons with DMD was $22.1 \pm 4.7$ (range: 15-30). Seventeen of the sons began to use a mechanical ventilator during the transition period (Table 2). The youngest son in the study did not use a ventilator. 
[Insert Tables 1 and 2 about here]

\subsection{Data Collection}

The mean length of the primary interview was $59.6 \pm 18.5$ min (range: $34-106)$. These semistructured interviews were conducted in the participants' home in Japanese by the first author. A topic guide for the semi-structured interviews was discussed and developed by the researchers (Table 3). Each interview was audio recorded (Sony IC RECORDER: ICD-UX512, Tokyo, Japan).

[Insert Table 3 about here]

All participants were observed outside of the interview at least once, while participating in daily life activities and situations with their DMD sons. During observations, the focus was on how the parent(s) provided care for their son, how and when they supported their son, and how they communicated with their DMD son. Field notes were taken about observations. The observations and interviews combined took over 200 hours.

The fieldwork and data collection took place from October 2012 through January 2014.

\subsection{Coding and Analyses}

The grounded theory uses constant comparison to analyze qualitative data [29]. This approach is useful because data are analyzed during collection; that is, after each interview was transcribed, the data were coded [29]. We used a recognized qualitative data management program, NVIVO10 (QSR International), in all phases of analysis from inputting data to generating a theory.

The first author reread each transcribed interview and coded each topic in the interview into as many specific categories as possible. The field notes were used to assist in understanding the interview data. Objectivity was verified by two experts in qualitative health science research who reviewed the interview data and codes. Following these steps, the codes were reviewed and combined into categories by M.Y. and the experts in tandem to guard against subjective interpretation. When disputes arose 
about different interpretations of codes or categories, the field notes were reviewed. We conducted a second interview if necessary to reach consensus. Fourteen participants participated in second

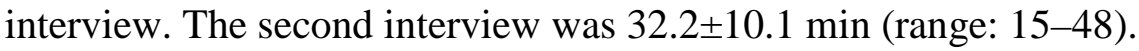

The categories formed by the codes were carefully reviewed each time new data were entered. Codes were continuously compared with the previous categories of topics in the group classifying the data. During the coding, the structure of the relationship between categories was identified. The grounded theory approach typically continues to add more individuals to the sample until theoretical saturation is reached [31]; saturation was confirmed when there were no new codes or categories. We determined that the identified concepts were adequate for interpretation of the categories, which defined the theory.

One bilingual translator translated the interviews into English. This forward translation was carried out carefully; when necessary, interview data were used during translation to confirm the participants’ original meaning. A native English speaker reviewed the translated codes before the codes were back translated by a different bilingual translator. Forward and back-translation was necessary to ensure the participants’ original meaning was maintained.

\subsection{Ethical Considerations}

This study was approved 9 October 2012 by the Medical Ethics Committee of Kyoto University (Approval No. 1013). Our study conformed to the principles set by the Declaration of Helsinki. Informed consent from the participants was obtained both verbally and in writing. To ensure anonymity, participants’ names did not appear on the field notes or any research documents. All participants were informed that their participation was voluntary and that they could withdraw from the study at any time without penalty. 


\section{Results}

The interview data yielded 93 codes in 11 categories. These categories of parenting behavior with sons with DMD were distributed across three domains: emotional, physical, and determination. Although the parents changed behaviors during the transition period, they were a strong influence on their sons throughout the transition. An example of a category and codes are shown in Table 4. A summary of the relationships of these concepts is in Figure 1.

[Insert Table 4 and Figure 1 about here]

\subsection{Emotional Domain}

This domain contains two categories: sympathizing and encouraging. The parents believed that they ought to support their sons emotionally in the future because DMD is a progressive terminal disease. The parents were aware that these two behaviors had been maintained and strengthened through the transition to adulthood. One mother of a 30 year-old son (the oldest of DMD son) expressed that her son recognized his life had become more difficult in the last 15 years. She told that she has always been trying to sympathize and encourage her son. Some parents noted that these two behaviors were carried over from childhood. The participants believed there was no one (except another parent) who could take the place of a parent in offering sympathy and encouragement.

\subsubsection{Sympathizing}

The parents thought their sons were susceptible to embarrassment, disappointment, irritation, or anxiety due to the progression of DMD. Parents tried to relieve these feelings by listening closely to sons’ concerns in daily life. The parents hoped to be the best in sympathizing with their sons. Their 
sons often experienced negative feelings in their daily life, for example, not being able to participate in the same activities as their peers because of a wheelchair or mechanical ventilation or becoming upset when they were unable to move. Parents thought their sons were generally happy, but also full of worries. One participant commented,

At night, my son sometimes says, “Lay down with me, mother.” I say, “Aren’t you ashamed of yourself, a grown man?” But... in secret, I sometimes lie down by his side just like when he was a little boy... And I listen to what happened to him during the day. Maybe he is anxious. I am the only one he talks to about his worries.

\subsubsection{Encouraging}

Parents also offered encouragement to their sons during the transition to adulthood; this was also carried over from childhood. The participants were eager to bring out their sons’ spiritual strength to overcome difficulties or obstacles. Participants encouraged their sons at every opportunity, especially when their sons lost courage.

My son had some hard days before getting used to life with the ventilator. During these days, I encouraged him, "you will soon figure it out, and you can breathe more easily. Then you will be able to do more. We're almost there." I just kept on encouraging him.

\subsection{Physical Domain}

There are five categories in the physical domain: providing care, entrusting, handing over, understanding, and providing backup. The behavior "providing care” is manifested by "entrusting” and “handing over.” Later, two new behaviors emerged, “understanding” and “providing backup.” These four behaviors lasted late into the transition period. These new behaviors were related to the parents feeling the need to continue care and support their son in the event of an emergency. 


\subsubsection{Providing care}

Parents provided medically advanced care and physical support for their sons. When the sons were in their mid-teen years, parents were responsible for all their physical care. Even when their sons became young adults, some parents continued to provide all the care for their sons. One mother with a 20-year-old son reported that she still could not entrust using the bag valve mask to her sons' home health aides.

My son usually uses a bag valve mask while bathing. Usually, we leave other tasks up to the home health aides. But the bag valve mask is my job. Sooner or later, I will trust someone else. But not yet, because using the bag valve mask requires a knack for doing it. That's my opinion. Of course, someday it will be for him to decide. But I decided to not to trust anybody else now. As noted by this mother, many parents did not persist in taking full responsibility for their sons' care. These parents recognized that providing full care should be slowly transferred; this recognition is displayed in the following categories. Providing care declined and four behaviors increased as their sons came into adulthood.

\subsubsection{Handing over}

This category refers to transferring authority for care management to their sons with DMD. Although this category is similar to respecting independent determination or supporting selfdetermination, this category focuses on the transfer of substantial management authority, particularly as it applies to physical support and medical. The parents recognized that their sons had typical psychosocial development. Therefore, they recognized that their sons would able to sense their physical condition and direct self-care needs as adults. They hoped their son would have an independent life owing to self-management, even as their DMD progressed in the future. However, parents also worried 
that their sons tended to be naturally anaclitic due to physical dependency. Therefore, participants consciously handed over care management to their sons as they grew up. Handing over was connected to the Entrusting category, and these two behaviors were accomplished incrementally. If the parents could not entrust their sons' care to home health aides, they could not hand over care management for their sons.

My son is the only one who can understand his physical condition. But he says, "Yes" to everything he is asked. Once, I asked, "Why do you say yes all the time?” He said, "Because it is easy." ... Sure, saying yes is easy. Doesn't he give a damn about his self-care? It is not another person's affair. It's his problem. I think acting that way will make him a dependent personality. This won't do. So, I have him take care of the physical matters.

\subsubsection{Entrusting}

Trust, in home health aides and others, is necessary if parents are to step back from their role as care providers. Entrusting and handing over are simultaneous during the transition to adulthood. All of the participants learned complex and refined the specialized health care to prevent their son from contracting pneumonia, ileus, and/or bedsores. The participants were deeply concerned about their sons' future as they become older. At some point in time, the parent will not be able to perform all the necessary specialized care. Hence, parents must teach home health aides how to care for their son in detail.

We have to get two or three reliable care workers... experienced caregivers... who can provide care instead of me.

One mother taught helpers precisely how to protect the olecranon from bedsores. 
This green towel is put under the elbow joint. Above the chest. A little too far. Yes, exactly at that point. Then this big towel... fold, fold, fold... fold three times and set under the mattress... Yes. OK, then set the flapped side... outside. You know, it hurts when the towel directly touches his elbow. So, you have to make it so it doesn't directly touch. Make a dent in the towel. Yes....

\subsubsection{Providing backup}

The parents are always prepared to provide care for their son in an emergency or an accident. The parents believe that their son may not receive help from his regular experienced care workers in an emergency or an accident. The parents live with a sense of impending crisis because their son cannot live without a mechanical ventilator and care.

We [he and his wife] have to always be ready if our son calls for help. It's our duty. Such as... if an earthquake occurs, his regular helpers [home health aides] may be taking care of their families. As a matter of fact, we don't know if our son will get the help he needs.

Another mother said,

If he married somebody...I mean if he has a wife, she may place a priority on his life... I can imagine that as very reassuring. But, I can't really believe it. You know, no one else can put him first like we do.

\subsubsection{Understanding}

This category has several meanings. It means to understand their sons’ latest physical condition, living conditions, and care methods. They hope that their sons can manage their own lives and care providers can provide appropriate care during the transition to adulthood. However, because the parents are always prepared to provide backup, they have to understand their sons’ current condition, 
particularly his health status. Parents did not want to meddle, but intended to affectionately watch their sons’ management of their physical conditions, living arrangements, and caregiving.

I know, so long as we live, my brain knows that his life cannot be without hardship. But, I can't help being anxious about him... particularly his physical condition or treatments. So, I'm always trying to understand his condition.

\subsection{Determination Domain}

This domain contains five categories: advocating, supporting self-determination, swaying, and respecting independent determination. When their sons were young, parents guided their sons in health promotion, social inclusion, safety, and energy conservation [32]. In the transition to adulthood, parents hoped that their sons could gain self-respect and self-determination, as well as directing their own health care.

\subsubsection{Advocating}

While their sons were children, parents played the role of advocates. Parents had a long history with a DMD son; it began even before their son knew he had a disease. When their son was young, the choice of care and rehabilitation were left up to the parents. Participants had a right and a duty to determine the appropriate time to speak to their son about his progressive disease. Advocating was especially important in the late teen years. One parent said,

When my son's schoolteacher asked his opinion about the future, he gave no answer and gave me a look like, “Mom, please answer for me?”... I said, “You can’t speak for yourself?” But, sometimes I can't help but give my opinion instead of his... maybe it is his opinion, too... instead of letting him answer. I know that's not really good." 
However, as their sons become adults, parents changed this behavior into supporting self-determination because the parents hoped their sons could make decisions as socially and mentally well-developed young adults.

\subsubsection{Supporting self-determination}

The parents had raised their sons to engage in self-determination. It began with small matters. One mother explained,

Once, my son was invited to an informal party. Since he was not yet in his twenties at that time, I usually arranged for a helper [an aide]. But on that particular day, I made him do it by himself... I told him, “Arrange your helpers by yourself if necessary. Think by yourself and you can handle it.”

The parents recognized that self-determination had added importance as DMD progressed because their sons would face declining mobility and increasing physical dependency. Another father reported an episode that describes how he realized the need for supporting self-determination.

When my son was in his late teens, we were told by his doctor, "It is rather rude of you to speak for your son. Your son is almost a young man." We thank him for that... I may have to distance myself from my son for his own good. ... Teenagers typically hope to challenge various things. But ...we parents may unconsciously prevent such challenges. We often hear that young people with DMD look childish. Our doctor expressed his concern about this.

\subsubsection{Swaying}

This category grew out of advocating. While participants increased respect for their sons' selfdetermination and did not meddle in their sons’ decisions, they did not hesitate to sway their son’s 
decisions by voicing their opinions. The parents worried more than their sons did about a future with a terminal disease. Sometimes parents raised doubts about their son's decisions because they were anxious for his physical conditions. For example, parents responded to their sons' desire for independent living and leaving their home with insisting that that was hardly realistic. The parents explained that swaying their sons' decisions was for their sons' own good.

I can't help putting a word in when he is making decisions. I believe it will be helpful to my son.

\subsubsection{Respecting independent determination}

This category came out of supporting self-determination. Respecting independent determination was present modestly in their sons' childhood. Their sons were capable of making decisions, and the parents respected their sons' determination. Parents hoped that their sons would experience a typical psychosocial development.

If our son wants to do something, what we parents can do is only support him? 


\section{Discussion}

The increasing number of individuals with technology-dependent DMD has led to pressing concerns about quality of life in adolescence and adulthood. The current study examined parenting behavior with older sons with DMD. This unprecedented study revealed that parents play an important role in the life of young adults with DMD. Recent studies investigating the role and attitude of parents living with ventilator-dependent children with neuromuscular diseases, including DMD, described parenting experiences as a "lifeline” and "living in a house of cards" [24, 25]. Even though the parents in these studies carried over some behaviors from childhood, the parents in our study changed their behaviors with their sons with DMD as their sons transitioned to adulthood. We named this change of parenting behavior "becoming a backup carer.” The results implied that parents intended to hold an important position in the lives of their sons with DMD even as they entered adulthood. We identified three major issues: psychological support, the aging of the caregiver parents and concomitant emergency and specialized care needs, and parents’ intervention in the self-determination of their adult sons.

4.1. Psychological support of individuals with DMD in the transition to adulthood

The majority of existing studies on psychological stress have focused on boys in their late teens with DMD [33-37]. Recent studies of individuals with DMD revealed that the need for psychological and emotional support increased as they grew into adulthood [33]. As one mother said in the interview, “No one except for me [mother] can support him mentally," this study found that parents with DMD recognized and tried to meet their sons’ psychological and emotional needs without enough support from specialists. We can only report the parents’ perceptions of the needs for emotional support because we did not interview their DMD sons in this study. The emotional distress of the patients with DMD in this transition period should be addressed in future research. 
4.2. Aging of the caregiver parents and concomitant emergency and specialized care needs

Separation from parental care is "taboo" for young adults with DMD [8]. Our study found supportive evidence for this assertion. Because they provided more elaborate care as their sons aged, parents understood the details of caregiving and their sons' conditions. The main issue of concern is the aging of parents; this will become a serious issue in medically advanced countries. In this study, Japanese parents seemed willing to hand over care management to their sons. This seems opposite to the report of Schrans et al., which noted that some of the DMD families might face a shock in the transition from family-oriented care to DMD individual-centered care. [8]. Although further research is needed, one of the reasons for Japanese parents' "handing over” behavior is trust in their the sons' home health aides who provide highly specialized care for their sons’ individual needs. This may also be related to supporting and respecting their sons' self-determination, which is another topic that requires further research. We suggest that determining a primary caregiver who provides care to the son on behalf of the parents, similar to a primary-nurse in the home care system, will lighten the burden of the backup role and worry that puts pressure on parents. A support system for emergency needs should be developed. In Japan, a few local governments have begun implementing a registration system of ventilator users [38, 39]. This system dispatches physicians and medical teams quickly and accurately to reach and assist ventilator users, especially those in independent living, when an earthquake, flood, or accident occurs. However, many Japanese local governments and other countries have not developed and installed such systems. We suggest that individuals with DMD have an expert caregiver who lives in the neighborhood; this person can be a great support for individuals with DMD and their parents in a disaster.

4.3. Parents' intervention in the development of self-determination of adult sons with DMD 
Penner, Cantor, and Siegal [40] reported the determination of a young man with DMD who decided not to use his long-term ventilator. His mother was shocked and rejected his decision at first, but she later accepted this decision due to the medical team's efforts to include her in the end-of-life conversation. They stated that young adults with DMD have a legal right to refuse treatment, and their caretakers had an ethical duty to respect their independence. However, they also emphasized the importance of interactive decision making by adult sons and their parents. Based on the results of our study, this advice for medical providers should be taken to heart. We found that parents intended to respect their sons’ independent decisions; however, parents sometimes could not accept their sons’ decisions despite this commitment. Parents' “swaying” behavior toward their sons' determination may be associated with worrying about their sons’ health. In our study one mother said to her son, “Can you really handle your health without us [the parents]?” and seemed more worried than her son did. This supports the findings of a study by Uzark et al. [41], which found a poor concordance in worry about health between the parents’ proxy-repots and sons' self-reports. As these researchers reported, such disagreement in the perceptions of parents and DMD sons about their sons’ health is remarkable. Family, medical care specialists, and home health aides should have open and frequent conversations about the decisions of sons and families about care and treatments. These group conversations must begin in childhood, when parents are the sole advocates for their sons. We should support the expression of determination of a son with DMD from young age, while offering praise to the parents for their son's independent decision-making ability because consistent parenting is essential to the development of this skill and independence.

\subsection{Study Limitations}

The beginning and end of the transition to adulthood in DMD patients is not clear, much as the transition period to young adulthood cannot be defined by a specific age in typically developing 
children. We cannot assert that the period of transition is exactly from 15 to 30 years of age; it may be that the transition begins earlier. It is likely that parents of DMD sons under 15 or over 30 years of age may have different experiences. Further studies, including families with younger sons, are necessary to identify an appropriate age range for this transition. Although we hope that these results offer suggestions for individuals with DMD and their parents in other countries and cultures, these findings may not generalize to all parents of DMD sons or to countries other than Japan. Further studies are required in different countries and cultures.

Finally, we did not interview the DMD sons in this study. Future research should include both parents and sons to develop a more complete picture of the transition to adulthood in DMD men and their parents.

\section{Conclusion}

The population of young adults with DMD has been increasing worldwide, and these individuals and their families are facing the transition to adulthood. Generally, young adults become independent and simultaneously change the parent-child relationships. However, individuals with DMD are more or less dependent upon their parents due to the progressive nature of their disease. This study revealed that parental behavior during the transition to adulthood was driven by the parents' desires to increase their sons' well-being. Aging parents will not be able to provide the same level of caregiving for their sons with DMD, and physicians, other health care professionals, and supporters should be aware of the need for assistance during this transition. This study demonstrated that parents and sons need this additional support. The identified issues of psychological support—-the aging of the caregiver parents and concomitant emergency and specialized care needs, and parent's intervention in the self-determination of their adult sons_-are important indicators of the challenges for DMD 
individuals and their families in the transition to adulthood. 


\section{References}

[1] Leung DG, Wagner KR. Therapeutic advances in muscular dystrophy. Ann

Neurolo 2013;74(3):404-11. doi:10.1002/ana.23989; 10.1002/ana.23989

[2] Moat SJ, Bradley DM, Salmon R, et al. Newborn bloodspot screening for Duchenne muscular dystrophy: 21 years experience in Wales (UK). Eur J Human Genet 2013;21(10):1049-53. doi:10.1038/ejhg.2012.301; 10.1038/ejhg.2012.301

[3] Buyse GM, Goemans N, van den Hauwe M, et al. Idebenone as a novel, therapeutic approach for Duchenne muscular dystrophy: Results from a 12 month, double-blind, randomized placebo-controlled trial. Neuromuscul Disord 2011;21(6):396-405. doi:10.1016/j.nmd.2011.02.016;

10.1016/j.nmd.2011.02.016

[4] Kohler M, Clarenbach CF, Böni L, et al. Quality of life, physical disability, and respiratory impairment in Duchenne muscular dystrophy. Am J Respir Crit Care Med 2005;172(8):1032-6. doi:10.1164/rccm.200503-322OC

[5] Eagle M, Baudouin SV, Chandler C, et al. Survival in Duchenne muscular dystrophy: Improvements in life expectancy since 1967 and the impact of home nocturnal ventilation. Neuromuscul Disord 2002; 12(10):926-9.

[6] Kohler M, Clarenbach CF, Bahler C, et al. Disability and survival in Duchenne muscular dystrophy. J Neurol Neurosurg Psychiatry 2009;80(3):320-5. doi:10.1136/jnnp.2007.141721; 10.1136/jnnp.2007.141721

[7] Peter NG, Forke CM, Ginsburg KR, et al. Transition from pediatric to adult care: Internists’ perspectives. Pediatrics 2009;23(2):417-23. doi:10.1542/peds.2008-0740; 10.1542/peds.2008-0740 
[8] Schrans DG, Abbott D, Peay HL, et al. Transition in Duchenne muscular dystrophy: An expert meeting report and description of transition needs in an emergent patient population: (Parent Project Muscular Dystrophy Transition Expert Meeting 17-18 June 2011, Amsterdam, The Netherlands). Neuromuscul Disord 2013;23(3):283-6. doi:10.1016/j.nmd.2012.08.009; 10.1016/j.nmd.2012.08.009

[9] Abbott D, Carpenter J, Bushby K. Transition to adulthood for young men with Duchenne muscular dystrophy: Research from the UK. Neuromuscul Disord 2012;22(5):445-6.

doi:10.1016/j.nmd.2012.02.004; 10.1016/j.nmd.2012.02.004

[10] Coleman JC, Hendry LB. Nature of Adolescence. Fourth Edition. New York, Routledge, 2011.

[11] Arnett JJ. Emerging adulthood: A theory of development from the late teens through the twenties. Am Psychol 2000;55(5):469-80. doi:10.1037//0003-066X.55.5.469

[12] Bynner J. Rethinking the youth phase of the life-course: The case for emerging adulthood? J Youth Stud 2005;8(4):367-84.

[13] Arnett JJ. Emerging adulthood: The winding road from the late teens through the twenties. New York, Oxford University Press, 2004.

[14] American Academy of Pediatrics, American Academy of Family Physicians, American College of Physicians-American Society of Internal Medicine. A consensus statement on health care transitions for young adults with special health care needs. Pediatrics 2002;110(6 Pt 2):1304-6.

[15] Buchanan DC, LaBarbera CJ, Roelofs R, et al. Reactions of families to children with Duchenne muscular dystrophy. Gen Hosp Psychiatry 1979;1(3):262-9. 
[16] Witte, RA. The psychosocial impact of a progressive physical handicap and terminal illness (Duchenne muscular dystrophy) on adolescents and their families. Brit J Med Psychol 1985;58(Pt 2):179-87.

[17] Abi Daoud MS, Dooley JM, Gordon KE. Depression in parents of children with Duchenne muscular dystrophy. Pediatr Neurol 2004;31(1):16-9. doi:10.1016/j.pediatrneurol.2004.01.011

[18] Webb CL. Parents’ perspectives on coping with Duchenne muscular dystrophy. Child Care Health Dev 2005;31(4):385-96. doi:10.1111/j.1365-2214.2005.00518.x

[19] Kenneson A, Bobo, JK. The effect of caregiving on women in families with Duchenne/Becker muscular dystrophy. Health \& Social Care in the Community 2010;18(5):520-8. doi:10.1111/j.13652524.2010.00930.x

[20] Pangalila RF, van den Bos GA, Stam HJ, et al. Subjective caregiver burden of parents of adults with duchenne muscular dystrophy. Disability and Rehabilitation 2012;34(12):988-96. doi:10.3109/09638288.2011.628738

[21] Nereo NE, Fee RJ, Hinton VJ. Parental stress in mothers of boys with Duchenne muscular dystrophy. J Pediatr Psychol 2003;28(7):473-84.

[22] Carnevale FA, Alexander E, Davis M, et al. Daily living with distress and enrichment: The moral experience of families with ventilator-assisted children at home. Pediatrics 2006;117(1):e48-60. doi:10.1542/peds.2005-0789

[23] Samson A, Tomiak E, Dimillo J, et al. The lived experience of hope among parents of a child with Duchenne muscular dystrophy: Perceiving the human being beyond the illness. Chronic Ill 2009;5(2):103-14. doi:10.1177/1742395309104343; 10.1177/1742395309104343 
[24] O’Brien ME. Living in a house of cards: Family experiences with long-term childhood technology dependence. J Pediatr Nurs 2001;16(1):13-22. doi:10.1053/jpdn.2001.20548

[25] Mah JK, Thannhauser JE, McNeil DA, et al. Being the lifeline: The parent experience of caring for a child with neuromuscular disease on home mechanical ventilation. Neuromuscul Disord 2008;18(12):983-8. doi:10.1016/j.nmd.2008.09.001; 10.1016/j.nmd.2008.09.001

[26] Blumer H. Symbolic interactionism. Perspective and method. Berkeley, University of California Press, 1986.

[27] Dev I. Grounding grounded theory. Guidelines for qualitative inquiry. San Diego, Academic Press, 1999.

[28] Jeon, YH. The application of grounded theory and symbolic interactionism. Scand J Caring Sci 2004;18(3):249-56. doi:10.1111/j.1471-6712.2004.00287.x

[29] Glaser BG, Strauss AL. The discovery of grounded theory: Strategies for qualitative research. Chicago, Transaction Publishers, 1967.

[30] Cooper CR. Cultural perspectives on continuity and change in adolescents’ relationships. In: R Montemayor, GR Adams, TP Gullotta, (Eds.), Personal relationships during adolescence. Advances in adolescent development, an annual book series, Vol. 6. Thousand Oaks, CA, Sage Publications, 1994, pp. 78-100.

[31] Starks H, Trinidad SB. Choose your method: A comparison of phenomenology, discourse analysis, and grounded theory. Qual Health Res 2007;17(10):1372-80. doi:10.1177/1049732307307031 
[32] Antle, BJ, Mills W, Steele C, eta al. An exploratory study of parents' approaches to health promotion in families of adolescents with physical disabilities. Child: Care, Health and Development, 2008;34(2):185-93. doi:10.1111/j.1365-2214.2007.00782.x [doi]

[33] Bothwell JE, Dooley JM, Gordon KE, et al. Duchenne muscular dystrophy--parental perceptions. Clin Pediatr (Phila) 2002;41(2):105-9.

[34] Imura, O. [Psychological support for patients with muscular dystrophy] Kin-dystrophy kanjya he no sinriteki support. Brain Nerve 2011;63(11):1245-52 (in Japanese).

[35] Hendriksen JG, Poysky JT, Schrans DG, et al. Psychosocial adjustment in males with Duchenne muscular dystrophy: Psychometric properties and clinical utility of a parent-report questionnaire. J Pediatr Psychol 2009;34(1):69-78. doi:10.1093/jpepsy/jsn067; 10.1093/jpepsy/jsn067

[36] Fee RJ, Hinton VJ. Resilience in children diagnosed with a chronic neuromuscular disorder. J Dev Behav Pediatr 2011;32(9):644-50. doi:10.1097/DBP.0b013e318235d614;

10.1097/DBP.0b013e318235d614

[37] Polakoff RJ, Morton AA, Koch KD, et al. The psychosocial and cognitive impact of Duchenne’s muscular dystrophy. Semin Pediatr Neurol 1998;5(2):116-23.

[38] Hatanaka H, Miki S, Yuasa N, Akiyama K. [Conducting disaster assistance drills for patients who receive a home ventilator care] Zaitaku jinkou kokyuki souchaku kanjya ni okeru saigaiji sien kunren no jisshi. Gan To Kagaku Ryoho 2010;37(Suppl 2):201-3 (in Japanese).

[49] Hyogo Prefecture, Department of Welfare, Office of Health, Section of Disease Control, Subsection of Intractable Disease. The emergency guideline for individuals with home mechanical 
ventilator living in Hyogo prefecture (Hyogo-ken zaitaku jinkou kokyuki souchaku kanjya saigaiji sien sisin). Nanbyo to Zaitaku Kea 2011;17(2):63-5 (in Japanese).

[40] Penner L, Cantor RM, Siegel L. Joseph’s wishes: Ethical decision-making in Duchenne muscular dystrophy. Mt Sinai J Med 2010;77(4):394-7. doi:10.1002/msj.20196; 10.1002/msj.20196

[41] Uzark K, King E, Cripe L, et al. Health-related quality of life in children and adolescents with duchenne muscular dystrophy. Pediatrics 2012;130(6):e1559-66. doi:10.1542/peds.2012-0858 


\section{Figure legend}

Figure 1. Changes in parenting behavior during their sons’ transition to adulthood.

This figure represents the development of the three domains (emotional, physical, and determination) from top to bottom. In the emotional domain, the roles of sympathizing and encouraging mutually complete each other and continue throughout the transition. In the physical domain, providing care develops into handing over and entrusting, which becomes providing backup and understanding. In the decision-making domain, parents were advocating, which grew into supporting self-determination as their sons attained adulthood. At the end of the transition period, swaying grew out of advocating and respecting independent determination developed from supporting self-determination. While swaying and respecting may appear to be opposites, they coexist. We named the changes in parenting behavior “becoming a backup.” 


\section{Figure 1}

parenting sons with Duchenne muscular dystrophy transitioning into adulthood

DMD Sons' Age

15

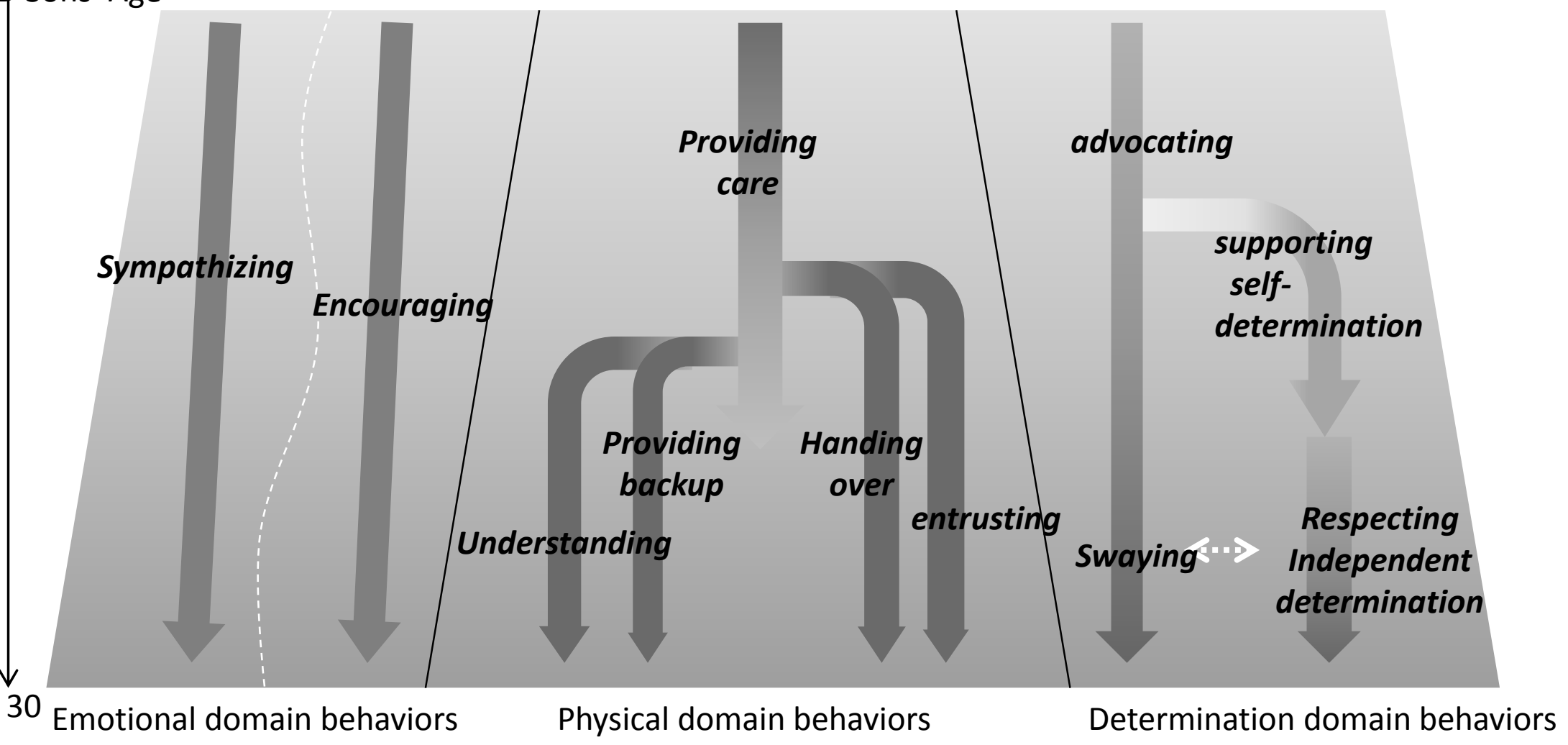

Physical domain behaviors
Determination domain behaviors 
Table 1. Characteristics of participants $(\mathrm{N}=18)$

Father/Mother

$4 / 14$

Age of the participants

40-49

4

50-59

13

60-69

Age of son with DMD

15-19

$20-24$

6

25-29

5

30

1

Mean \pm SD (Range)

$22.1 \pm 4.7(15-30)$

Religious beliefs

No

Yes

Marital status

Married

Divorced

Widowed

Living with son with DMD

Yes

No

4

Employment status

Full-time homemaker

15

Full-time worker 
Major source of income

Employment

Welfare 3

Unknown 
Table 2. Types of mechanical ventilators

\begin{tabular}{|c|c|c|c|c|c|}
\hline \multicolumn{2}{|c|}{ Son's age $(\mathrm{N}=18)$} & $15-19(n=6)$ & $20-24(n=6)$ & $25-29(n=5)$ & $30(\mathrm{n}=1)$ \\
\hline \multicolumn{2}{|l|}{ No ventilator } & 1 & 0 & 0 & 0 \\
\hline \multirow{3}{*}{$\begin{array}{l}\text { Non-invasive } \\
\text { ventilator }\end{array}$} & Night & 2 & 1 & 1 & 0 \\
\hline & $\begin{array}{l}\text { Night and sometimes } \\
\text { day }\end{array}$ & 2 & 2 & 0 & 0 \\
\hline & Continuous & 1 & 3 & 4 & 1 \\
\hline \multicolumn{2}{|l|}{ Tracheostomy } & 0 & 0 & 1 & 0 \\
\hline
\end{tabular}


Table 3. Semi-structured interview topic guide

\section{BEFORE INTERVIEW QUESTIONS ${ }^{a}$}

1. Age of parent and son

2. Religious beliefs

3. Marital status
4. Employment status

5. Major source of income

6. Living with son or not

\section{INTERVIEW TOPIC GUIDE}

1. Please tell me about raising your son.

*Ask the participant to speak about past parenting experiences.

2. Tell me about your current life with your son

*Ask the participant to speak about recent experiences focused on mid-teens to current age of his/her son.

If further prompting is necessary:

How do you communicate with your son?

How do you behave in such situations?

What did you intend by doing that?

\footnotetext{
${ }^{a}$ Pay attention to privacy protection; it is desirable that each interview is conducted in private room.

${ }^{\mathrm{b}}$ Each interview time should be about one hour.
} 
Table.4 An example of category and its codes

\begin{tabular}{|c|c|}
\hline Category & Codes \\
\hline \multirow[t]{6}{*}{ Entrusting } & $\begin{array}{l}\text { This green towel is put under the elbow joint. Above the } \\
\text { chest. A little too far. Yes, exactly at that point. Then this big } \\
\text { towel... fold, fold, fold... fold three times and set under the } \\
\text { mattress... Yes. OK, then set the flapped side... outside. You } \\
\text { know, it hurts when the towel directly touches his elbow. So, } \\
\text { you have to make it so it doesn’t directly touch. Make a dent } \\
\text { in the towel. Yes....(parent A) }\end{array}$ \\
\hline & $\begin{array}{l}\text { All care, all help... every, every day of his life... You may } \\
\text { think "an exaggeration"..., but } 1 \text { millimeter, ... he needs that } \\
\text { slight difference of position for his pillow to replaced } \\
\text { correctly. Teaching the aides all of these things is my duty. } \\
\text { When we get an untrained recruit, I have to teach him } \\
\text { everything. (parent C) }\end{array}$ \\
\hline & $\begin{array}{l}\text { We will soon get older. Like elder-to-elder nursing care*, } \\
\text { providing care for him will become hard job for us... So, I } \\
\text { think we parents should definitely get support from helpers } \\
\text { [home health aides] and medical professionals... (*Elder-to- } \\
\text { elder nursing care in Japan means that an elderly person over } \\
60 \text { years old is taking care his/her elderly family.) (parent D) }\end{array}$ \\
\hline & $\begin{array}{l}\text { As I getting old, I'm anxious about how we will continue } \\
\text { twenty-four hour care for my son. ...Especially night care... or } \\
\text { weekend...Indeed, we must rely on helpers [home health } \\
\text { aides]....we need more skillful aides....(parent F) }\end{array}$ \\
\hline & $\begin{array}{l}\text { The biggest problem is burden of continual care for him. We } \\
\text { need a better system to support Duchenne muscular dystrophy } \\
\text { patients and families. Also, we and our son grow old. I'm } \\
\text { afraid we will go down together. So, we have the right to ask } \\
\text { for support. We have to leave to our aides what we trust them } \\
\text { to do. (parent G) }\end{array}$ \\
\hline & $\begin{array}{l}\text { We have to get two or three reliable care } \\
\text { workers...experienced caregivers... who can provide care } \\
\text { instead of me. (parent } \mathrm{H} \text { ) }\end{array}$ \\
\hline
\end{tabular}


I'm gonna entrust his care to the aides. We will have to entrust many aides. ... I'm always thinking...in case anything should happen to me...I have to be ready to leave the caregiving to his aides. (parent $\mathrm{J}$ )

In future, we may trust our aides to care of him. (parent M)

We started looking for aides because my lower back hurt. I am not young anymore. ...Each type of care requires a technique... Even when we hold up him, we have to be careful of many points. ... We [I and my husband and I] have to teach helpers [aides] how to care for him. (parent $\mathrm{N}$ )

I'm afraid. What if something happens to me? What shall we do if I should fail to care him because of my serious illness? We should prepare to to have care him in such situations. So, we should entrust his care on others. (parent R) 